\title{
Fuzzy Linear Programming Approach for Determining the Production Amounts in Poultry Industry
}

\author{
Çağatay Teke ${ }^{1}$, and Baha Güney ${ }^{2}$
}

\begin{abstract}
In recent years, rapid and correct decision making is crucial for both people and enterprises. However, uncertainty makes decision-making difficult. Fuzzy logic is used for coping with this situation. Thus, fuzzy linear programming models are developed in order to handle uncertainty in objective function and the constraints. In this study, a problem of a factory in poultry industry is investigated, required data is obtained and the problem is figured out as a fuzzy linear programming model. The model is solved using Zimmerman approach which is one of the approaches for fuzzy linear programming. As a result, the solution gives the amount of production for each product type in order to gain maximum profit.
\end{abstract}

Keywords-Fuzzy linear programming, fuzzy logic, linear programming, poultry industry

\section{INTRODUCTION}

$\mathrm{D}$ ECISION making (DM) helps executives for determining the best alternative in any decision problem which comprise of procedures and criteria. DM generally depend on Decision Support Systems (DSS) tools [1].

Fuzzy set theory can be optimum approach to cope with uncertainties in decision problems modelled with linear programming. [2] There are different techniques in fuzzy linear programming. A common characteristic of these techniques is the preliminary defuzzification of the fuzzy variables [1].

Zadeh and Bellman propounded the notion of maximizing the decision for decision making problems. Tanaka et al adjusted it for mathematical programming problems. A fuzzy approach concerning multi-objective linear programming problems was introduced by Zimmermann. Also, Lai and Hwang, Tong Shaocheng, Buckley, among others, deal with that whole parameters are fuzzy. Studies in recent years suggest new techniques with the purpose of ranking fuzzy numbers and coming to an optimal solution [3].

\section{FUZZY SETS}

Fuzzy set theory is based on the logic underpinned the types of reasoning, which are ambiguous instead of precise [6]. In real life, classical logic is insufficient for many situations and events. When a person asks what the weather is, the answer can be very cold, cold, warm, hot, very hot and extremely hot. Style of thinking and data processing of people can process the uncertain data. However, traditional

Ç. Teke ${ }^{1}$ is with the Industrial Engineering Department, University of Sakarya, Sakarya, 54100 Turkey (phone: +90-264-2957404; e-mail: cteke@ sakarya.edu.tr).

B. Güney ${ }^{2}$ is with the Industrial Engineering Department, University of Sakarya, Sakarya, 54100 Turkey (e-mail: bguney@ sakarya.edu.tr). computer technology cannot overcome this type of data [4].

In fuzzy logic, a proposition can be either true or false. Moreover, it can be also partially true and partially false. That is, an element can have two memberships in different sets simultaneously. In this case, trueness degree of the proposition range from zero to one. On the other hand, it also has '1-trueness degree' as degree of falsity [4].

System modelling is used for symbolizing a real physical system. While this process perform, mathematical formula or equation is used. Most of physical systems include uncertainty and they are too sophisticated to model it completely. This type of systems can model with fuzzy logic approximately. Thus, fuzzy system modelling plays an important role to describe complicated real world systems $[5]$.

\section{FUZZY LINEAR PROGRAMMING}

\section{A. Linear Programming}

A Linear Programming (LP) problem is a special case of Mathematical Programming problem. From an analytical perspective, a mathematical program attempts to identify an extreme (minimum or maximum) point of a function, which furthermore satisfies a set of constraints. Linear programming is the objective function and the problem constraints are linear [6].

A classical model of LP, also called a crisp LP model, may have the following formulation:

$$
\begin{aligned}
& \operatorname{Max} C x \\
& \text { s.t. } \\
& A_{i} x \leq b_{i} \quad i \exists, \ldots, n
\end{aligned}
$$

in which $\mathrm{x}$ is an $\mathrm{n} \times 1$ alternative set, $\mathrm{C}$ is $\mathrm{a} 1 \times \mathrm{n}$ coefficients of an objective function, $A_{i}$ is an $m \times n$ matrix of coefficients of constraints and $b_{i}$ is an $m \times 1$ right-hand sides.

The traditional problems of LP are solved with LINDO optimization software and obtain the optimal solution in a precise way. If coefficients of constraints, objective function or the right-hand sides are imprecise, in other words, being fuzzy numbers, traditional algorithms of LP are unsuitable to solve the fuzzy problem and to obtain the optimization.

In the real world, the coefficients are typically imprecise numbers because of insufficient information, for instance, technological coefficients. Many researchers formed Fuzzy Linear Programming of various types, invented approaches to convert them into crisp LP, and finally solved the problems with available software [7]. 


\section{B. Fuzzy Linear Programming}

Fuzzy linear programming (FLP) follows from the fact that classical linear programming is often insufficient in practical situations. In reality, certain coefficients that appear in classical LP problems may not be well-defined, either because their values depend on other parameters or because they cannot be precisely assessed and only qualitative estimates of these coefficients are available. FLP is an extension of classical linear programming and deals with imprecise coefficients by using fuzzy variables [8].

We consider the FLP Problem

$$
\begin{aligned}
& \operatorname{Max} \tilde{Z}=\tilde{C}^{T} x \\
& \text { s.t. } \\
& \tilde{A} \tilde{\sim} \tilde{b} \\
& x \geq 0
\end{aligned}
$$

The solution of this problem is to find the possibility distribution of the optional objective function Z. Many researchers had handled this problem by converting the fuzzy objective function and the fuzzy constraints into crisp ones [9].

\section{TYPES OF FUZZY LINEAR PROGRAMMING}

Fuzzy linear programming model divides into parts in terms of fuzzy coefficients. For instance, while objective function is fuzzy, constraints cannot be fuzzy.

\section{A. Objective Function is Fuzzy}

In a real life, there are many situations that parameters of objective function (profit and cost) are imprecise. FLP model of this was propounded by Verdegay.

\section{B. Right-Hand Sides are Fuzzy}

There are two approach for this type of problem. While first approach concerning asymmetric models belongs to Verdegay, second approach concerning symmetric model belongs to Werners. Fuzzy

\section{Right-Hand Sides and Coefficients of Constrains are}

Negoita and Sularia developed an approach for this type of FLP model.

\section{Objective Function and Constrains are Fuzzy}

As it is understood the title, in this model, both objective function and constrains involve fuzziness. Zimmermann and Chanas have different approaches about it.

\section{E. All Coefficients are Fuzzy}

Sometimes, all coefficients can be fuzzy in the problem. Carlsson and Korhonen developed the approach for this.

\section{ZIMMERMANN METHOD}

A LP with a fuzzy objective function and fuzzy inequalities shown by Zimmermann is indicated as follows: [7]

$$
\begin{aligned}
& C^{T} \tilde{\tilde{x}} \tilde{b}_{0} \\
& (A x)_{i} \tilde{\leq} b_{i} \\
& x \geq 0 \quad i=1,2, \ldots, n
\end{aligned}
$$

Inequality is a symmetrical model of which the objective function becomes one constraint. To write a general formulation, inequality is converted to a matrix form as [7]:

$$
-C^{T} x \stackrel{\sim}{\leq}-b_{0}
$$

In which

$$
B=\left[\begin{array}{c}
-C \\
A_{i}
\end{array}\right] \quad b=\left[\begin{array}{c}
-b_{0} \\
b_{i}
\end{array}\right]
$$

The inequalities of constraint signify "be as small as possible or equal" that can be allowed to violate the right-hand side $b$ by extending some value. The degree of violation is represented by membership function as [7]:

$$
\begin{aligned}
& \mu_{0}(x)=\left\{\begin{array}{cc}
0 & \text {,i } C x \leq b_{0}-d_{0} \\
1-\frac{b_{0}-C x}{d_{0}} & \text { if } b_{0}-d_{0} \leq C x \leq b_{0} \\
1 & \text {,i } C x \leq b_{0}
\end{array}\right\} \\
& \mu_{i}(x)=\left\{\begin{array}{cc}
0 & \text { if }\left(A x_{i}\right) \geq b_{i}+d_{i} \\
1-\frac{(A x)_{i}-b_{i}}{d_{i}} & \text {, if } b_{i} \leq(A x)_{i} \leq b_{i}+d_{i} \\
1 & \text { if }(A x)_{i} \leq b_{i}
\end{array}\right\}
\end{aligned}
$$

In which $\mathrm{d}$ is a matrix of admissible violation.

This problem can be transformed by introducing the auxiliary variable $\lambda$ as follows:

$$
\begin{aligned}
& \mu_{0}(x) \geq \lambda \\
& \mu_{i}(x) \geq \lambda \\
& \lambda \in[0,1]
\end{aligned}
$$

This problem can be stated as linear programming as follows:

$$
\begin{aligned}
& \operatorname{Max} \lambda \\
& \text { s.t. } \\
& \mu_{0}(x) \geq \lambda \\
& \mu_{i}(x) \geq \lambda \\
& \lambda \in[0,1]
\end{aligned}
$$

This problem was shown with membership functions of fuzzy objective function and fuzzy constrains as follows: 


\section{$\operatorname{Max} \lambda$}

s.t.

$$
\begin{aligned}
& 1-\frac{b_{0}-C x}{d_{0}} \geq \lambda \\
& 1-\frac{(A x)_{i}-b_{i}}{d_{i}} \geq \lambda, \forall i \\
& \lambda \in[0,1] \\
& x \geq 0
\end{aligned}
$$

After some simplification, fuzzy linear programming model obtains as follows:

$$
\begin{aligned}
& \operatorname{Max} \lambda \\
& \text { s.t. } \\
& C^{T} x-\lambda d_{0} \geq b_{0}-d_{0} \\
& (A x)_{i}+\lambda d_{i} \leq b_{i}+d_{i}, \forall i \\
& \lambda \in[0,1] \\
& x \geq 0
\end{aligned}
$$

TABLE I

DATA ABOUT THE APPLICATION

\begin{tabular}{|c|c|c|c|c|c|c|}
\hline \multicolumn{1}{|c|}{ Variables } & $\mathrm{X}_{1}$ & $\mathrm{X}_{2}$ & $\mathrm{X}_{3}$ & $\mathrm{X}_{4}$ & $\mathrm{X}_{5}$ & $\mathrm{X}_{6}$ \\
\hline Variable name & 120 & 0.8 & 2.8 & 0.4 & 3.2 & 1.4 \\
\hline Unit profits (TRY per item) & 20 & 4150 & 2200 & 2300 & 100 & 1800 \\
\hline Expected demands (item per month) & 5 & 500 & 400 & 200 & 10 & 600 \\
\hline Tolerances for demands (item per month) & 16.098 & 1.227 & 6.77 & 0.603 & 13.5 & 0.65 \\
\hline Labour usage (minute per item) & \multicolumn{7}{|c|}{16,000} \\
\hline Expected profit (TRY) & \multicolumn{7}{|c|}{1300} \\
\hline Tolerance for profit (TRY) & \multicolumn{7}{|c|}{240,240} \\
\hline Monthly production capacity (item) & \multicolumn{7}{|c|}{} \\
\hline Monthly labour capacity (minute) &
\end{tabular}

\section{APPLICATION}

\section{A. Problem Definition}

Data used for the application was obtained a factory in poultry industry. It produces different poultry equipment. Since the expected profit and the demand of the product types are uncertain the problem is built as fuzzy linear programming model in order to determine production amounts per month for each product type for maximizing the profit. Data about the production and its constraints is given in Table I.

\section{B. FLP Model}

Problem was modelled as monthly basis. The fuzzy linear programming model of the problem is given below:

$$
\begin{array}{lc}
C^{T} x=120 x_{1}+0.8 x_{2}+2.8 x_{3}+0.4 x_{4} \\
3.2 x_{5}+1.4 x_{6} & \\
b_{0}=16,000 & d_{0}=1800 \\
b_{1}=20 & d_{1}=5 \\
b_{2}=4150 & d=500 \\
b_{3}=2200 & d=400 \\
b_{4}=2300 & d=200 \\
b_{5}=100 & d_{5}=10 \\
b_{6}=1800 & d=600
\end{array}
$$

\section{$\operatorname{Max} \lambda$}

s.t.

$$
\begin{aligned}
& 120 x_{1}+0.8 x_{2}+2.8 x_{3}+0.4 x_{4}+ \\
& 3.2 x_{5}+1.4 x_{6}-1800 \lambda \geq 14,200 \\
& x_{1}+5 \lambda \leq 25 \\
& x_{2}+500 \lambda \leq 4650 \\
& x_{3}+400 \lambda \leq 2600 \\
& x_{4}+200 \lambda \leq 2500 \\
& x_{5}+10 \lambda \leq 110 \\
& x_{6}+600 \lambda \leq 2400 \\
& x_{1}+x_{2}+x_{3}+x_{4}+x_{5}+x_{6} \leq 13,000 \\
& 16.098 x_{1}+1.227 x_{2}+6.77 x_{3}+0.603 x_{4}+ \\
& 13.5 x_{5}+0.65 x_{6} \leq 240,240 \\
& \lambda \in[0,1] \\
& x_{i} \geq 0 \\
& i=1,2, \ldots 6 \\
& \forall x_{i} \in Z^{+}
\end{aligned}
$$

\section{Problem Solution}

FLP model of the problem has been solved using Lindo optimization software. Results of the solution are given in Table II and Table III.

As can be seen from the solution, the factory should produce $20 \mathrm{x}_{1}, 4192 \mathrm{x}_{2}, 2234 \mathrm{x}_{3}, 2317 \mathrm{x}_{4}, 100 \mathrm{x}_{5}, 1851 \mathrm{x}_{6}$.

TABLE II

RESULTS OF THE SOLUTION

\begin{tabular}{|c|c|c|}
\hline Variable & Value & Reduced Cost \\
\hline$\lambda$ & 0.915 & 0 \\
\hline $\mathrm{X}_{1}$ & 20 & -0.066667 \\
\hline $\mathrm{X}_{2}$ & 4192 & -0.000444 \\
\hline $\mathrm{X}_{3}$ & 2234 & -0.001556 \\
\hline $\mathrm{X}_{4}$ & 2317 & -0.000222 \\
\hline $\mathrm{X}_{5}$ & 100 & -0.001778 \\
\hline $\mathrm{X}_{6}$ & 1851 & -0.000778 \\
\hline
\end{tabular}


TABLE III

RESULTS OF THE SOLUTION

\begin{tabular}{|c|c|c|}
\hline Row & Slack or Surplus & Dual Price \\
\hline 2 & 0.000000 & -0.000556 \\
\hline 3 & 0.425000 & 0.000000 \\
\hline 4 & 0.500023 & 0.000000 \\
\hline 5 & 0.000018 & 0.000000 \\
\hline 6 & 0.000009 & 0.000000 \\
\hline 7 & 0.850000 & 0.000000 \\
\hline 8 & 0.000027 & 0.000000 \\
\hline 9 & 2286 & 0.000000 \\
\hline 10 & 215699.9 & 0.000000 \\
\hline
\end{tabular}

Total profit of the factory can be calculated as follows:

$$
\begin{aligned}
& (120 \times 20)+(0.8 \times 4192)+(2.8 \times 2234)+(0.4 \times 2317)+ \\
& (3.2 \times 100)+(1.4 \times 1851)=15,847 \text { TRY }
\end{aligned}
$$

\section{CONCLUSION}

In this study, a problem of a factory in poultry industry was modelled by using fuzzy linear programming. Because the model has fuzziness in both objective function and constraints, it was solved by using Zimmerman approach which is one of the approaches for fuzzy linear programming. As a result, the solution gives the amount of production for each product type in order to gain maximum profit.

\section{REFERENCES}

[1] F. Nucci, C. Cavallo, and A. Grieco, "A fuzzy linear programming approach to mix product selection problem," IEEE, 1-4244-1210-2/07, 2007.

http://dx.doi.org/10.1109/fuzzy.2007.4295606

[2] S. M. Guu, Y. K. Wu, "Two-phase approach for solving the fuzzy linear programming problems," Fuzzy Sets and Systems, 107:191-195, 1999. http://dx.doi.org/10.1109/fuzzy.2007.4295606

[3] A. N. Gani, C. Duraisamy, C. Veeramani, "A note on fuzzy linear programming problem using L-R fuzzy number,” International Journal of Algorithms, Computing and Mathematics, 3:93-106, 2009.

[4] B. Yıldız, "Finansal analizde yapay zeka," Beta 2009.

[5] G. Chen, T. T. Pham, "Introduction to Fuzzy Sets, Fuzzy Logic and Fuzzy Control Systems," CRC Press, 2000. http://dx.doi.org/10.1201/9781420039818

[6] E. Dervişoğlu, "Fuzzy Linear Programming: Review and Implementation," Sabanci University, İstanbul, 2005.

[7] C. S. Lee, C. G. Wen, "River assimilative capacity analysis via fuzzy linear programming," Fuzzy Sets and Systems, 79:191-201, 1996. http://dx.doi.org/10.1016/0165-0114(95)00171-9

[8] J. Ren, T. B. Sheridan, “Optimization with fuzzy linear programming and fuzzy knowledge base," IEEE, 0-7803- 1896-X/94, 1994.

[9] R. N. Gasimov, K. Yenilmez, "Solving Fuzzy Linear Programming Problems with Linear Membership Functions," Turk J Math, 26:375-396, 2002. 